\title{
Effect of thermomechanical treatments on the formation of submicrocrystalline structural states and mechanical properties of metastable austenitic steel
}

\author{
I.Yu. Litovchenko ${ }^{1,2,}$, S.A. Akkuzin ${ }^{2}$, N.A. Polekhina ${ }^{1,2}$, A.N. Tyumentsev ${ }^{1,2}$ \\ †litovchenko@spti.tsu.ru
}

${ }^{1}$ Institute of Strength Physics and Materials Science SB RAS, 2/4 Akademicheskii av., Tomsk, 634055, Russia

${ }^{2}$ National Research Tomsk State University, 36 Lenin av., Tomsk, 634050, Russia

\begin{abstract}
The thermomechanical treatments with sequential increase in temperature of deformation were used to form submicrocrystalline structural states in AISI 321 metastable austenitic steel. The initial deformation were carried out with cooling in liquid nitrogen $(T=77 \mathrm{~K}$ ) following by deformation in the temperature range of $T=300-1173 \mathrm{~K}$. Unlike severe plastic deformation, we used total degree of true deformation $e<1$. The features of the structural states and mechanical properties of steel at various stages of thermomechanical treatments have been investigated. It is shown that the low-temperature deformation promotes intensive $\left(\gamma \rightarrow \alpha^{\prime}\right)$-martensitic transformation with the formation of $\approx 54-60 \%$ of $\alpha^{\prime}$-martensite. After the subsequent deformation at temperatures of $300-773 \mathrm{~K}$ the volume content of $\alpha^{\prime}$-martensite is $60-80 \%$. At higher deformation temperatures (873-973 K) the reverse $\left(\alpha^{\prime} \rightarrow \gamma\right)$ martensitic transformation occurs with a decrease in the martensite content to $11-45 \%$ and the formation of submicrocrystalline structure of "packet austenite". The deformation at $T>973 \mathrm{~K}$ contributes to dynamic recovery and dynamic recrystallization. Thermomechanical treatments can improve the yield strength of steel up to $\approx 1300 \mathrm{MPa}$ at the minimum values of elongation. Additional annealing after thermomechanical treatments allow to control the ratio of austenite-martensite phases, size and imperfection of submicrocrystalline fragments, as well as the strength and plastic properties of steel. The high strength properties are due to submicrocrystalline structure, which is formed as a result of direct and reverse $\gamma \rightarrow \alpha^{\prime} \rightarrow \gamma$ martensitic transformations.
\end{abstract}

Keywords: metastable austenitic steel, thermomechanical treatment, martensitic transformation.

\section{Влияние термомеханических обработок на формирование субмикрокристаллических структурных состояний и механи- ческие свойства метастабильной аустенитной стали}

\author{
Литовченко И.Ю. ${ }^{1,2, \dagger}$, Аккузин С.А. ${ }^{2}$, Полехина Н.А. ${ }^{1,2}$, Тюменцев А.Н., ${ }^{1,2}$ \\ ${ }^{1}$ Институт физики прочности и материаловедения СО РАН, пр. Академический 2/4, 634055, Томск, Россия \\ ${ }^{2}$ Национальный Исследовательский Томский государственный университет, пр. Ленина 36, 634050 Томск, Россия
}

Для формирования субмикрокристаллических структурных состояний в метастабильной аустенитной стали 08Х18Н10Т (типа AISI 321) использованы термомеханические обработки, включающие пластическую деформацию с последовательным повышением температуры. Начальная деформация осуществлялась с охлаждением в жидком азоте ( $T=77 \mathrm{~K})$, последующая в интервале температур $T=300-1173 \mathrm{~K}$. В отличие от методов интенсивной пластической деформации, в процессе указанных обработок общая степень истинной деформации $e<1$. Исследованы особенности структурных состояний и механические свойства стали на различных этапах термомеханических обработок. Показано, что низкотемпературная деформация способствует интенсивному $\left(\gamma \rightarrow \alpha^{\prime}\right)$-мартенситному превращению с формированием $\approx 54-60 \% \alpha^{\prime}$-мартенсита. В процессе последующей деформации при температурах 300 - 773 К объемное содержание $\alpha^{\prime}$-мартенсита несколько возрастает и достигает $\approx 60-80 \%$. При более высокой (873-973 K) температуре деформации происходит обратное $\left(\alpha^{\prime} \rightarrow \gamma\right)$-мартенситное превращение с уменьшением содержания мартенсита до $\approx 11-45 \%$ и формированием субмикрокристаллической структуры “пакетного аустенита”. Деформация при T>973 К способствует динамическому возврату и динамической рекристаллизации. Термомеханические обработки позволяют повысить предел текучести стали до $\approx 1300$ МПа при минимальных значениях относительного удлинения. Дополнительные отжиги после термомеханических обработок позволяют управлять соотношением фаз аустенит-мартенсит, размерами и дефектностью субмикрокристаллических фрагментов, а также прочностными и пластическими свойствами стали. Высокие прочностные свойства обусловлены субмикрокристаллической структурой, которая формируется в результате прямых и обратных $\gamma \rightarrow \alpha^{\prime} \rightarrow \gamma$ мартенситных превращений.

Ключевые слова: метастабильная аустенитная сталь, термомеханическая обработка, мартенситные превращения. 


\section{1. Введение}

Повышение прочностных свойств хромоникелевых аустенитных сталей возможно путем создания в них субмикрокристаллических структурных состояний в процессе различных термомеханических обработок [1-7]. Для эффективного измельчения зерна в условиях пластической деформации в аустенитной области [1-3] требуются большие степени деформации $(e \approx 2-6$, где $e-$ истинная деформация). В метастабильных аустенитных сталях субмикрокристаллические структурные состояния могут быть получены в процессе прямых $\left(\gamma \rightarrow \alpha^{\prime}\right)$-мартенситных превращений при охлаждении и (или) деформации и обратных $\left(\alpha^{\prime} \rightarrow \gamma\right)$-превращений при нагреве. В работах [4-7] показано, что пластическая деформация метастабильных аустенитных сталей с охлаждением до температуры жидкого азота $(T=77$ K) способствует интенсивному $\left(\gamma \rightarrow \alpha^{\prime}\right)$-мартенситному превращению с формированием до $80 \% \alpha^{\prime}$-мартенсита. Показано [5-7], что последующая теплая деформация двухфазной $\left(\gamma+\alpha^{\prime}\right)$-структуры способствует обратному $\left(\alpha^{\prime} \rightarrow \gamma\right)$-превращению и формированию субмикрокристаллических структурных состояний. Однако влияние температуры деформации на структуру и механические свойства метастабильной аустенитной стали в двухфазном состоянии изучено недостаточно.

В настоящей работе представлены результаты исследований особенностей структурно-фазовых состояний и механических свойств метастабильной аустенитной стали после термомеханических обработок, состоящих из низкотемпературной деформации и последующей деформации при различных температурах.

\section{2. Материал и методики эксперимента}

Переддеформацией образцы метастабильной аустенитной стали $08 \mathrm{X} 18 \mathrm{H} 10 \mathrm{~T}(\mathrm{Fe}-18.02 \% \mathrm{Cr}-9.77 \% \mathrm{Ni}-1.4 \% \mathrm{Mn}-0.59 \% \mathrm{Ti})$ подвергались отжигу при $1373 \mathrm{~K} 1$ ч. с последующей закалкой в воду. Исследования проводили на двух партиях образцов, различающихся размерами и условиями деформации. В первой партии исходный размер образцов составлял $\approx 30 \times 20 \times 12 \mathrm{мм}$, а во второй $\approx 30 \times 20 \times 2 \mathrm{Mм}$. Низкотемпературную деформацию осуществляли за несколько проходов с общей степенью деформации $\varepsilon \approx 20 \%$. Перед помещением в прокатный стан и между проходами образцы выдерживали при температуре жидкого азота ( $T=77 \mathrm{~K})$.

После низкотемпературной деформации первая партия образцов подвергалась деформации при температурах $300-873 \mathrm{~K}$ за 2 прохода с общей степенью деформации $\varepsilon \approx 40 \%$ с последующей закалкой в воду. Теплую деформацию $\varepsilon \approx 20-30 \%$ второй партии образцов осуществляли за 1 проход после нагрева в печи до температур $T=873-1173 \mathrm{~K}$. После термомеханических обработок отдельные образцы подвергали кратковременным отжигам $1073 \mathrm{~K}, 200$ c.

Электронно-микроскопические исследования проводили на просвечивающем электронном микроскопе Philips CM-12 при ускоряющем напряжении 120 кB. Тонкие фольги готовили методом электролитической поли- ровки в электролите, содержащем 450 мл ортофосфорной кислоты и 50 г хромового ангидрида.

Изменение фазового состава исследовали на рентгеновском дифрактометре Shimadzu XRD -6000 в $\mathrm{Cu} K_{a}$ излучении в геометрии Брэгга-Брентано с фокусирующим монохроматором на вторичном пучке. Объемная доля фаз определялась в программе POWDER CELL 2.4 с учетом текстуры обеих фаз.

Механические испытания осуществляли методом активного растяжения при комнатной температуре со скоростью деформации $\varepsilon \approx 2 \times 10^{-3} \mathrm{c}^{-1}$ на образцах в форме двойных лопаток с размерами рабочей части $13 \times 2 \times 1$ мм.

\section{3. Результаты исследований и их обсуждение}

Рентгеноструктурный анализ (РСА) показал, что деформация с охлаждением в жидком азоте приводит к интенсивному развитию $\left(\gamma \rightarrow \alpha^{\prime}\right)$-мартенситного превращения с формированием $\approx 54-60 \% \alpha^{\prime}$-мартенсита, что несколько меньше, чем получено ранее (до $\approx 75 \%$ ) в работах $[5,7]$. Анализ результатов показал, что содержание мартенсита в значительной степени зависит от температуры образца в прокатном стане. Без специального охлаждения валков эта температура определяется размерами образца и интервалом времени между началом деформации и нахождением образца в жидком азоте. При этом количество проходов и общая задаваемая деформация в меньшей степени влияют на объемную долю мартенсита.

Электронно-микроскопические исследования показали, что дефектная структура стали представлена тонкими ламелями субмикро- и нанокристаллического масштаба, состоящими из пакетов $\alpha^{\prime}$-мартенсита, микродвойников аустенита и отдельных пластин $\varepsilon$-мартенсита [5-7]. Указанное структурное состояние обеспечивает высокие прочностные свойства стали - предел текучести $\sigma_{0.1} \approx 920-940$ МПа, относительное удлинение $\delta \approx 5-15 \%$.

Последующая деформация в интервале температур $\mathrm{T}=300-773 \mathrm{~K}$ способствует продолжению $\left(\gamma \rightarrow \alpha^{\prime}\right)$-мартенситного превращения. Рентгеноструктурный анализ показал, что после такой деформации объемная доля $\alpha^{\prime}$-мартенсита составляет $\approx 60-80 \%$ (Табл. 1). Электронно-микроскопические исследования выявили формирование ламельной двухфазной $\left(\alpha^{\prime}+\gamma\right)$-структуры с высоким содержанием пакетного $\alpha^{\prime}$-мартенсита (Рис. 1a,b). Полученное структурное состояние обеспечивает предел текучести стали 1120 - 1300 МПа при относительном удлинении $\delta \approx 3-4 \%$ (Табл. 1). Указанные значения прочности на $\approx 180-380$ МПа выше, чем после низкотемпературной деформации. Высокая прочность и низкие значения пластичности стали обусловлены ламельной структурой с высоким $(\approx 60-80 \%)$ содержанием пакетного $\alpha^{\prime}$-мартенсита.

Деформация с нагревом до $T=873 \mathrm{~K}$ (после низкотемпературной обработки) приводит к обратному $\left(\alpha^{\prime} \rightarrow \gamma\right)$-мартенситному превращению. Исследования методом РСА показали, что объемное содержание аустенита увеличивается и достигает $\approx 64 \%$ (Табл. 1 ).

Эти значения несколько меньше, чем полученные ранее (до $\approx 86 \%)$ в условиях аналогичной обработки $[5,7]$. 
Табл. 1. Фазовый состав и механические свойства стали.

Table 1. Phase composition and mechanical properties of steel.

\begin{tabular}{|c|c|c|c|c|c|}
\hline \multirow{2}{*}{$\begin{array}{l}\text { Режим обработки } \\
\text { Treatment }\end{array}$} & \multicolumn{2}{|c|}{$\begin{array}{l}\text { Фазовый состав } \\
\text { Phase composition }\end{array}$} & \multirow{2}{*}{$\begin{array}{l}\sigma_{0.1}, \mathrm{M \Pi а} \\
\sigma_{0.1}, \mathrm{MPa}\end{array}$} & \multirow{2}{*}{$\begin{array}{l}\sigma_{b}, \mathrm{M} \mathrm{M} \\
\sigma_{u^{\prime}}, \mathrm{MPa}\end{array}$} & \multirow[t]{2}{*}{$\delta, \%$} \\
\hline & $\alpha^{\prime}, \%$ & $\gamma, \%$ & & & \\
\hline $\begin{array}{c}\text { Низкотемпературная + прокатка, } T=300 \mathrm{~K} \\
\text { Low-temperature + rolling, } T=300 \mathrm{~K}\end{array}$ & 80 & 20 & 1210 & 1320 & 3 \\
\hline $\begin{array}{c}\text { Низкотемпературная прокатка + теплая прокатка, } T=673 \mathrm{~K} \\
\text { Low-temperature + warm rolling } T=673 \mathrm{~K}\end{array}$ & 60 & 40 & 1120 & 1250 & 4 \\
\hline $\begin{array}{c}\text { Низкотемпературная прокатка + теплая прокатка, } T=773 \mathrm{~K} \\
\text { Low-temperature + warm rolling } T=773 \mathrm{~K}\end{array}$ & 60 & 40 & 1300 & 1320 & 3 \\
\hline $\begin{array}{c}\text { Низкотемпературная + теплая прокатка, } T=873 \mathrm{~K} \\
\text { Low-temperature + warm rolling } T=873 \mathrm{~K}\end{array}$ & 36 & 64 & 1245 & 1390 & 5 \\
\hline $\begin{array}{c}\text { Низкотемпературная + теплая прокатка, } T=973 \mathrm{~K} \\
\text { Low-temperature + warm rolling, } T=973 \mathrm{~K}\end{array}$ & 11 & 89 & 840 & 1000 & 13 \\
\hline $\begin{array}{l}\text { Низкотемпературная + теплая прокатка, } T=1073 \mathrm{~K} \\
\text { Low-temperature + warm rolling, } T=1073 \mathrm{~K}\end{array}$ & 1 & 99 & 635 & 755 & 20 \\
\hline $\begin{array}{c}\text { Низкотемпературная + теплая прокатка, } T=1173 \mathrm{~K} \\
\text { Low-temperature + warm rolling, } T=1173 \mathrm{~K}\end{array}$ & 0 & 100 & 590 & 720 & 31 \\
\hline
\end{tabular}

Указанные отличия могут быть обусловлены разницей в температуре деформации без специального подогрева валков. Количество проходов и общая задаваемая степень деформации в меньшей степени влияют на объемное содержание аустенита. Значения, приведенные в таблице 1 , являются средними для двух партий образцов.

Электронно-микроскопические исследования выявили формирование ламельной преимущественно аустенитной структуры субмикрокристаллического масштаба с мало- и высокоугловыми, двойниковыми и близкими к ним разориентировками [5-7]. Средние размеры аустенитных ламелей $\approx 150-200$ нм. В отдельных ламелях обнаруживаются тонкие $(\approx 10-20$ нм $)$ нанодвойники, дефекты упаковки, а также высокая плотность дислокаций. По форме, размерам и разориентировкам аустенитные ламели подобны пакетному $\alpha^{\prime}$-мартенситу, что позволяет охарактеризовать полученное структурное состояние как “пакетный аустенит”, сформированный в результате прямых $\left(\gamma \rightarrow \alpha^{\prime}\right)$ - и обратных $\left(\alpha^{\prime} \rightarrow \gamma\right)$-мартенситных превращений $[6,7]$.

Механические испытания показали, что указанная термомеханическая обработка обеспечивает значение предела текучести $\sigma_{0.1} \approx 1245 \mathrm{MПа,} \mathrm{относительное}$ удлинение $\delta \approx 5 \%$ (Табл. 1). Полученные значения более чем на 300 МПа выше, чем после низкотемпературной деформации. В этом случае высокопрочное состояние стали обусловлено ламельной двухфазной субмикрокристаллической структурой “пакетного аустенита” и пакетного $\alpha^{\prime}$-мартенсита.

Повышение температуры деформации $(T=973 \mathrm{~K})$ способствует более интенсивному обратному $\left(\alpha^{\prime} \rightarrow \gamma\right)$-превращению, содержание аустенита составляет $\approx 89 \%$ (Табл. 1). Электронно-микроскопические исследования показали, что субмикрокристаллические структурные состояния при такой обработке сохраня- ются (Рис. 1c,d). Между аустенитными фрагментами наблюдаются как малоугловые, так и высокоугловые, а также двойниковые и близкие к ним разориентировки. В некоторых фрагментах дефекты практически отсутствуют, что свидетельствует о начале процессов динамического возврата и динамической рекристаллизации. В структуре обнаружены мелкодисперсные (до 10 нм) частицы TiC.

Прочность стали после такой обработки несколько снижается относительно рассмотренных выше обработок, тем не менее, она остается на достаточно высоком $\left(\sigma_{0.1} \approx 840 \mathrm{MПа)} \mathrm{уровне,} \mathrm{пластичность} \mathrm{возрастает}\right.$ $(\delta \approx 13 \%)$, Табл. 1. Указанные значения прочности обусловлены субмикрокристаллической преимущественно аустенитной структурой.

В процессе термомеханических обработок с деформацией при температурах $T=1073-1173 \mathrm{~K}$ реализуется почти полное обратное $\left(\alpha^{\prime} \rightarrow \gamma\right)$-превращение (Табл. 1$)$. Электронно-микроскопические исследования показали, что повышение температуры деформации приводит к развитию динамической рекристаллизации с существенным ростом размеров фрагментов аустенита (до нескольких мкм) и частиц $\mathrm{TiC}$ (до $200-250$ нм). Прочность стали после таких обработок ниже $\left(\sigma_{0.1} \approx 590-635 \mathrm{MПа}\right)$, по сравнению с рассмотренными выше обработками, пластичность возрастает $(\delta \approx 20-31 \%)$, Табл. 1 .

Кратковременные отжиги после термомеханических обработок (с прокаткой при $T=300-973$ К) способствуют обратному $\left(\alpha^{\prime} \rightarrow \gamma\right)$-превращению и увеличению объемной доли аустенита до 95\%. При этом сохраняется субмикрокристаллическое структурное состояние, в котором помимо ламельных фрагментов наблюдаются равноосные фрагменты с низкой плотностью дислокаций. В этом состоянии получены достаточно высокие прочностные $\left(\sigma_{0.1} \approx 795-890\right.$ МПа) и пластические $(14-24 \%)$ свойства. 


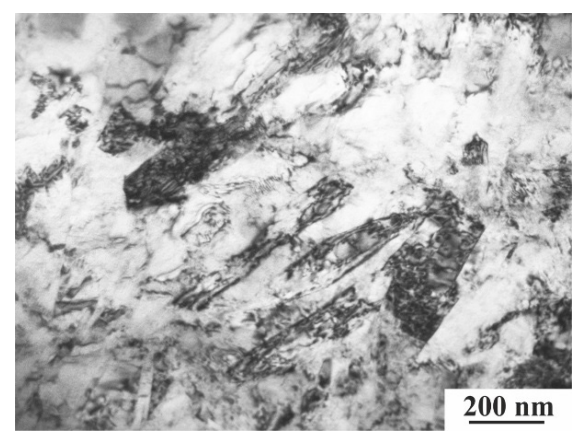

a

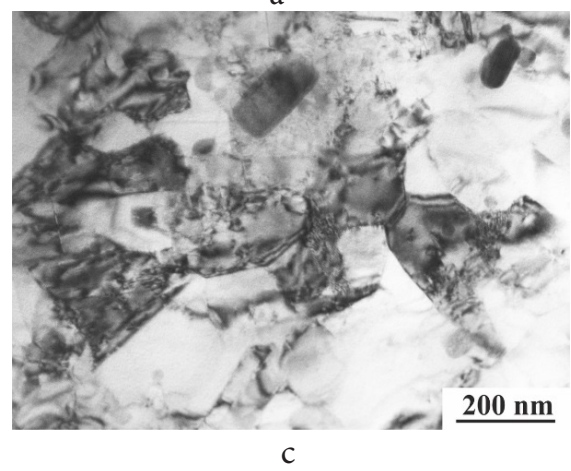

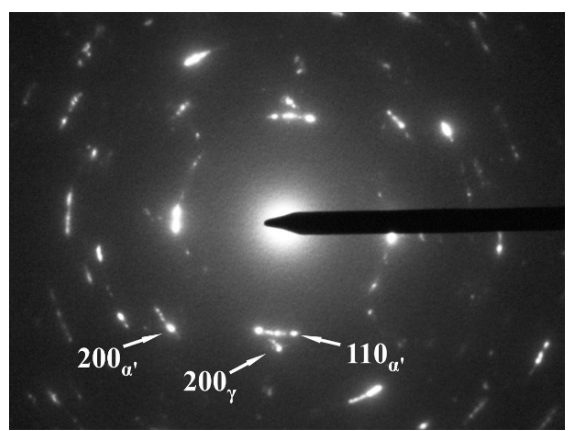

b

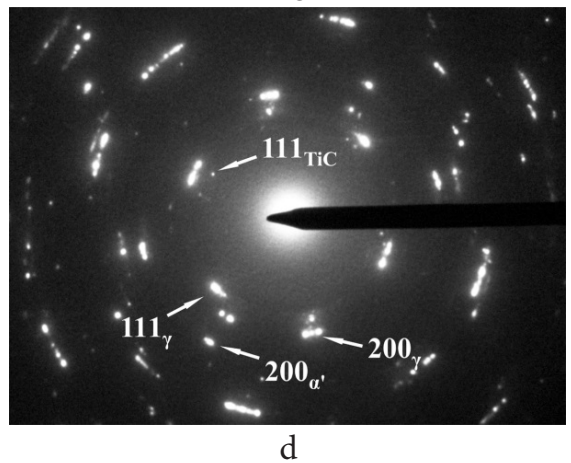

Рис. 1. Микроструктура стали после термомеханических обработок, состоящих из: (a), (b) - низкотемпературной и теплой деформации при $T=773 \mathrm{~K} ;(\mathrm{c}),(\mathrm{d})$ - низкотемпературной и теплой деформации при $T=973$ К. (a), (c) - светлопольные изображения; (b), (d) - микродифракционные картины.

Fig. 1. The microstructure of the steel after thermomechanical treatment, consisting of: (a), (b) - low-temperature and warm deformation at $T=773 \mathrm{~K}$; (c), (d) - low-temperature and warm deformation at $T=973 \mathrm{~K}$. (a), (c) - bright field images; (b), (d) - microdiffraction patterns.

\section{4. Выводы}

В процессе термомеханических обработок, состоящих из низкотемпературной и последующей деформации в интервале $T=300-973 \mathrm{~K}$ в метастабильной аустенитной стали получены субмикрокристаллические структурные состояния с различным соотношением фаз аустенит/мартенсит. В отличие от методов интенсивной пластической деформации использованы относительно малые степени деформации $(e<1)$.

Показано, что низкотемпературная и последующая деформации при $T=300-773 \mathrm{~K}$ способствуют прямому $\left(\gamma \rightarrow \alpha^{\prime}\right)$ - мартенситному превращению. В этих условиях высокие прочностные свойства (предел текучести до $1300 \mathrm{MПа)} \mathrm{обусловлены} \mathrm{значительным} \mathrm{(до} \approx 80 \%$ ) содержанием пакетного $\alpha^{\prime}$-мартенсита.

Повышение температуры деформации до $T=873$ - 973 К способствует обратному $\left(\alpha^{\prime} \rightarrow \gamma\right)$-мартенситному превращению и формированию ламельной субмикрокристаллической структуры “пакетного аустенита”. При этом достигаются высокие прочностные свойства (предел текучести до $1245 \mathrm{MПа).} \mathrm{Деформация}$ при $T \geq 1073 \mathrm{~K}$ приводит к динамическому возврату и динамической рекристаллизации, увеличению размеров фрагментов аустенита и снижению прочности.

Кратковременные отжиги после термомеханических обработок повышают содержание аустенита с сохранением субмикрокристаллической структуры. При этом достигнуты значения предела текучести до $\approx 890$ МПа, относительного удлинения до $\approx 24 \%$.
Благодарность/Acknowledgements. Исследования выполнены в рамках программы повышения конкурентоспособности ТГУ и при поддержке гранта РФФИ № 15-08-07416-а. Работа выполнена с использованием оборудования Томского материаловедческого иентра коллективного пользования ТГУ.

\section{Литература/References}

1. M. Tikhonova, A. Belyakov and R. Kaibyshev, Materials Science and Engineering A 564 (2013) 413-422. doi:10.1016/j.msea.2012.11.088.

2. Z. J. Zheng, Y. Gao, J. W. Liu and M. Zhu, Materials Science and Engineering A 639 (2015) 615-625. doi:10.1016/j. msea.2015.05.085.

3. S. Rajasekhara, L. P. Karjalainen, A. Kyrolainen and P. J. Ferreira, Materials Science and Engineering A 527 (2010) 1986 - 1996. doi:10.1016/j.msea.2009.11.037.

4. M. Eskandari, A. Kermanpur and A. Najafizadeh, Materials Letters 63 (2009) 1442 -1444. doi:10.1016/j. matlet.2009.03.043.

5. I. Yu. Litovchenko, S. A. Akkuzin, A. N. Tyumentsev and E.P. Naiden, AIP Conference Proceedings 1623 (2014) 343 - 346. doi:10.1063/1.4901490.

6. I. Yu. Litovchenko, S.A. Akkuzin, N.A. Polekhina, A.N. Tyumentsev and E.P. Naiden, AIP Conference Proceedings 1683 (2015) 020123-1-020123-4. doi:10.1063/1.4932813.

7. I.Yu. Litovchenko, S.A. Akkuzin, N.A. Polekhina, A. N. Tyumentsev and E. P. Naiden, Russian Physics Journal. 59(6) 782-787 (2016). doi:10.1007/s11182-016-0837-1. 